\title{
Filosofía del Dolor \\ Sobre la importancia de diferenciar el dolor físico y el sufrimiento moral
}

\author{
On the importance of diferenciate \\ physical pain and moral suffering
}

\author{
FRANCISCO JAVIER SUSO ALEA \\ Universidad de Salamanca
}

\begin{abstract}
RESUMEN
Se propone una distinción clave en la investigación de la experiencia dolorosa, tan común y tan desagradable para la experiencia humana. Los estudios que afrontan problemas afectados por un componente emocional poderoso nacen con el hándicap de la heterogeneidad de la experiencia emocional y la dificultad para aislar el sentimiento (experiencia subjetiva) de la emoción (respuesta idiosincrásica de origen evolutivo). Dolor físico y sufrimiento moral cumplen este requisito. El artículo valora las ventajas que aportaría al conocimiento del dolor físico, como experiencia humana, una distinción básica entre sufrimiento moral y dolor físico, en el convencimiento de que el concepto de sufrimiento a secas es inválido para una investigación socialmente útil y genera confusión. El asunto parece importante, porque el dolor físico es uno de los procesos neurológicos que más afectan nuestras vidas, por lo que su afrontamiento, previa comprensión, nos incumbe a todos durante toda la vida.
\end{abstract}

\author{
PALABRAS CLAVE \\ DOLOR; SUFRIMIENTO; CONOCIMIENTO; INVESTIGACIÓN; \\ CIENCIA; FILOSOFÍA
}

\begin{abstract}
We pose a key distinction in the research on the experience of the pain, which is so common and at the same time so unpleasant for humans. The studies that focus on problems with a powerful emotional component face the handicap of the diversity of emotional experience and the difficulty in isolating the feeling (subjective experience) of emotion (idiosyncratic response with an evolutionary origin). Physical pain and moral suffering are good examples
\end{abstract}


of such problems. This article discusses the advantages that a basic distinction between moral suffering and physical pain would bring to the knowledge of the latter as a human experience, inasmuch as the general concept of suffer is not only inadequate for a socially useful research but also is misleading. A better-understanding of this issue seems relevant since the physical pain is a neurological process that affects all of us throughout our lives.

KEYWORDS

PAIN, SUFFERING, KNOWLEDGE, RESEARCH, SCIENCE, PHILOSOPHY

AGRADECIMIENTOS

Quiero expresar mi agradecimiento al profesor Iago Ramos de la Facultad de Filosofía de la Universidad de Salamanca por su bonhomía, su buena voluntad y sus consejos.

\section{INTRODUCCIÓN}

Porque como los hombres han cubierto sus ideas con nombres, y el uso común ha establecido nombres conocidos para designar ciertas ideas, una afectada aplicación de esos nombres no podría menos que ser extremadamente ridícula

John Locke ${ }^{1}$

¿QUÉ SENTIDO TIENE LA ACTIVIDAD FILOSÓFICA HOY EN DÍA? Mucho, y a mi entender sustancial. Eso sí, a condición de que su orientación se corresponda con los intereses de la sociedad que aspira a mejorar. Todos los filósofos tienen en su seno el germen de la inquietud intelectual, como todos los corredores de gran fondo tienen una inquietud física que les atrapa. ${ }^{2}$ Un filósofo quiere conocer y comprender, igual que un científico, y esa aspiración al conocimiento le absorbe, le embriaga. El punto de conexión es claro; la interconexión, sin embargo, genera menos frutos de los que cabría esperar. La potencia de pensamiento de dos metodologías radicalmente diferentes no se debería desaprovechar, pero el humano, preso de su propia soberbia, tiende a minusvalorar la capacidad creativa de su propia especie en aquello que desconoce.

El saber filosófico no puede ser mera curiosidad ni erudición vacua. La filosofía se relaciona con la búsqueda de respuestas a lo que no las tiene, a lo que importa, a lo que subyace, a lo que nos intriga. El elemental charloteo o la incomprensible jerigonza son ajenos a la filosofía, y deben ser desterrados

1 Ver la Conclusión (51) del Libro III del 'Ensayo sobre el entendimiento humano', capítulo VI (Acerca de los nombres de las sustancias).

2 Pocos espectáculos resultan más turbadores que compartir durante 6 horas un autobús de maratonianos el día anterior a la competición. 
de ella. Los problemas ya resueltos, los asuntos que ya no se plantean o las dificultades que han sido superadas no pueden ser el núcleo de la investigación filosófica, si la filosofía apuesta por su supervivencia en el imaginario cultural.

El profesor Carlos París lo explica muy bien en la lección magistral que impartió con motivo de su nombramiento como Profesor Emérito de la Universidad Autónoma de Madrid:

[...] la filosofía actual solo puede ser desarrollada en estrecha relación con la ciencia; aún más ampliamente con todo el mundo de nuestra cultura [...] Evidentemente no me refiero a ninguna reducción de la filosofía a un mero metalenguaje, sino a la elaboración crítica de las estructuras reveladas y enriquecidas en la praxis (París, 1992, p. 16).

En la práctica de la medicina, un sparring entrenado contra el dolor y el sufrimiento, se convive diariamente con la experiencia dolorosa. El dolor es un asunto central, una encomienda diaria, pero habitualmente la pelea se desarrolla en penumbra. Una de las singularidades, debilitante en algunas ocasiones, del enfoque científico de un problema es que requiere presencia física, o lo que es lo mismo demanda objetivación y medición. El dolor, y el sufrimiento, son inaccesibles en plenitud al observador externo -el investigador-, en tanto que traducen relatos íntimos inasibles desde la distancia. Es mi propósito en este artículo orientar puntualmente la reflexión filosófica hacia un problema de alcance universal e interés ecuménico, que está muy lejos de poder considerarse resuelto, ni a nivel filosófico, ni a nivel científico. Me refiero, claro está, a la ardua cuestión del dolor, entendido como experiencia personal, como vivencia irrefutable e íntima. El dolor es algo que no deja a nadie indiferente y que a todo el mundo compete. Nadie es ajeno a la experiencia dolorosa. ${ }^{3}$

El dolor es objeto de reflexión filosófica, pero me parece pertinente observar cómo, tratándose de un tema de tanta enjundia, los filósofos tienden a integrar múltiples problemas bajo un epígrafe unitario sin alterar por ello su análisis. Es fácil encontrar artículos filosóficos, libros monográficos y trabajos colaborativos explícitamente orientados a pulsar la opinión de expertos pensadores sobre el asunto del dolor. En ellos se mezcla el sufrimiento de Edipo, ${ }^{4}$ con el dolor de

3 En realidad 'casi nadie', porque existen crueles situaciones de asimbolia dolorosa en las que la ausencia de sensibilidad dolorosa genera enormes trastornos a sus afectados. Esto es muy raro a nivel general (asimbolia total), pero relativamente frecuente a nivel local.

4 Morera de Guijarro, Juan Ignacio: 'En torno al sufrimiento de Edipo (tragedia y psicoanálisis)'. En González, Moisés (2006): Filosofia y dolor, pp. 91-119. 
la represión ${ }^{5}$ y la transmutación trágica del sufrimiento en Nietzsche. ${ }^{6}$ Ese no me parece el camino para ayudar a los ciudadanos que se ven afectados por una experiencia tan desleal.

En las investigaciones filosóficas sobre el tema que nos ocupa no acostumbra a diferenciarse dolor y sufrimiento, mezclándose el tratamiento de asuntos muy diversos bajo una perspectiva común. El 'sufrimiento moral' y el 'dolor físico' comparten, ciertamente, muchos aspectos, pero representan experiencias diferenciadas y diferenciables.

\section{SOBRE EL SUFRIMIENTO}

La palabra sufrimiento se emplea indistintamente para el dolor físico y el dolor moral que experimenta cualquier ser vivo. Al menos en español, sufrimiento semeja el enorme Pithos en que la hija de Hefesto guardaba todas las experiencias negativas de las que es capaz el ser humano, cualquiera que sea su origen, intensidad o filiación. El sufrimiento se acompaña de una intensa reacción emocional de ansiedad y frustración, pero no requiere necesariamente la presencia de dolor físico. 'Acompañe a mi suegra en el sufrimiento que le causó la muerte de su marido', 'empatizo con el sufrimiento del cautivo' o 'asistí impotente al sufrimiento que le generaba la pérdida de su mejor amigo' son ejemplos de ello. El sufrimiento, igual que el placer, se puede evocar mentalmente, incluso con gran intensidad, pero el dolor no se puede simular; solo se puede padecer o recordar. El sufrimiento -supuesto o verdadero- puede cohesionar comunidades si lo comparten, particularmente cuando se trata de una imposición invencible, o ser el germen en que anida un gran proyecto artístico. El dolor, en cambio, busca una respuesta individualizada, requiere contestación inmediata. Las personas que sufren cuadros crónicos relacionados con el dolor se reúnen buscando soluciones compartidas, previo asegurarse de la imposibilidad de contener el daño, pero a causa del sufrimiento perdurable que les inflige el cuadro doloroso y no durante las crisis de dolor, que nunca coinciden en el tiempo por su enorme variabilidad individual. Lo mismo sucede cuando creemos que el dolor supera cualquier posibilidad de control, es abrumadoramente insoportable y se mantiene en el tiempo o es imposible identificar la fuente del dolor.

El sufrimiento puede generar trastornos físicos, pero no tienen que consistir en dolor. Asistir a la agonía de un enfermo que padece fuertes dolores puede producir una intensa agitación corporal, boca seca, sudores, palpitaciones,

5 López Sáenz, M. ${ }^{a}$ Carmen: 'H. Marcuse (1898-1979): Trabajo y dolor como consecuencias de la represión’. En González, Moisés (2006): Filosofía y dolor, pp. 439-454.

6 Salgado Fernández, Enrique: 'Dolor y nihilismo. Nietzsche y la transmutación trágica del sufrimiento. En González, Moisés (2006): Filosofía y dolor, pp. 30-349. 
angustia, 1lanto, calambres musculares, etc., pero no dolor físico (salvo casos de acomodación empática extrema). En todas la Unidades de Cuidados Paliativos hay, entre otras muchas cosas, protocolos específicamente construidos para apoyar a los familiares de los que padecen. El sufrimiento se asocia con oscuridad, desconexión, letargo e incomunicación, mientras el dolor refiere más bien a inquietud, compañía, ayuda o, en ocasiones, insolencia. El sufrimiento es muy difícil de explicar, genera dificultad de comunicación y asocia alejamiento. El dolor, particularmente si es de causa desconocida, se expone, se explica, se señala. El sufrimiento es un enemigo interior; el dolor es un adversario exterior.

En 'El Padrino: Parte III' (Francis Ford Coppola, 1990), Al Pacino interpreta al benjamín de la estirpe mafiosa cuando se debe hacer cargo del imperio familiar, lo que le genera grandes dosis de sufrimiento personal, en ausencia de dolor. Inolvidable la secuencia final en la que el protagonista ve morir a su hija bajo la tiranía de una bala destinada a él. Nadie ha expresado mejor sin palabras el sufrimiento extremo y la desolación absoluta que el actor neoyorquino. Michael Corleone, muerto en vida, fallece solo y abandonado de todos, mientras la vida continua en un aislamiento total. Nunca entra en el drama el dolor físico como integrante del escenario, sencillamente porque no forma parte de la situación. Se puede argüir que el dolor siempre estuvo presente en nuestro mafioso preferido, pero en ese caso el empleo de la palabra 'dolor' sería metafórica (una traslación de sentido). El sufrimiento de origen psíquico propende al retraimiento y la incomunicación, mientras el ser humano que siente dolor por sus heridas físicas - $\mathrm{o}$ asimilables a ellas- busca acabar con esa situación, cualquiera que sea su causa o intensidad a la mayor brevedad.

Existen apropiaciones del dolor absolutamente inasibles para el sufrimiento. El dolor puede relacionarse con 'excitación' y 'placer' en la parafernalia masoquista o puede buscarse como señal de 'éxito', de 'superación'. En Un hombre llamado caballo, Richard Harris - un aristócrata inglés apresado por una tribu de indios sioux-sufre un tormento consistente en ser colgado de sus pectorales por las garras de un águila, para que las terribles cicatrices resultantes sirvan de ceremonia de iniciación y prueba irrefutable de su compromiso con el clan. Ninguna de estas situaciones puede relacionarse con el sufrimiento, excepto si se emplea el término en sentido figurado. Por el otro lado, hay significados próximos a sufrimiento (aflicción, sacrificio, mortificación, agobio, penuria, etc.) que no forman parte de la experiencia del dolor, ni en el sentido real ni en el figurado. Los dolientes que esperan ser atendidos por un cólico nefrítico en la sala de urgencias de un hospital sienten un dolor rabioso, pero no están apenados. Estas personas urgen una solución y su retraimiento es puramente físico: el objetivo es encontrar una postura que alivie el dolor, independientemente de la amargura de la existencia. 
El empleo de la palabra sufrimiento como sinónimo de dolor me parece desafortunado y, como intentaré mostrar a lo largo de este artículo, genera confusión y perjudica la investigación de un problema de gran calado, principalmente a nivel filosófico. A nivel científico, en la práctica médica concretamente, se discrimina bien el sufrimiento de un adolescente tras sufrir un injusto desarraigo, una humillación o un episodio de acoso - muy triste y deprimente, pero nada doloroso-, y el sufrimiento de una persona que padece una perforación del tímpano o le han pegado un tiro en el pie -muy doloroso, pero nada triste o deprimente-. El segundo caso no solamente no es luctuoso, sino que es muy estimulante y genera un comportamiento corporal absolutamente diferente al del primero. El lenguaje corporal es un extraordinario ayudante en la sala de urgencias o en la consulta médica.

Las condiciones más extremas de sufrimiento siempre son silenciosas, taciturnas, mudas. Las circunstancias que acompañan a casos extremos de sufrimiento (campos de concentración, guerras de trincheras, pérdidas de familiares, ...) no asocian ningún tipo de dolor, salvo que esas personas sean torturadas, tiroteadas o malheridas. La posibilidad de compartir el dolor-gritar tras una puñalada o agitarse en un intento de salvaguardar la vida- son estrategias de protección corporal que acompañan los dolores físicos, pero no los psíquicos. «El sufrimiento aísla a los hombres, les relaciona solo consigo mismos...El sufrimiento extremo privatiza al hombre completamente, destroza su capacidad de comunicación», dice con mucha razón Dorothee Sölle en su libro titulado 'Sufrimiento'? El dolor insensible es muy dañino para las personas y la sociedad. El dolor físico busca el acompañamiento, exige una solución, quema etapas, genera desplazamientos, busca complicidades, anhela respuestas inmediatas. ${ }^{8}$ El sufrimiento ha ido generando sus propias estrategias de afrontamiento, en forma de reflexión filosófica, meditación trascendental, sobreactuación de los sentidos (bulimia o erotomanía, por ejemplo), ejercicio del poder o satisfacciones estéticas. Nada que ver con la manera en que esperan ser apoyados los dolientes físicos. He aquí un interesante proyecto para la filosofía enrolada en la penetración del dolor: ¿cómo es posible que, bajo determinadas circunstancias, el dolor pueda ser gratificante?

A finales del siglo pasado, el prestigioso Hastings Center, fundado en 1969 por el filósofo Daniel Callahan y el psicoanalista Willard Gaylin, que se dedica al abordaje multidisciplinar de cuestiones éticas y sociales relacionadas con el cuidado de la salud, la ciencia y la tecnología, publicó un importante

7 Ver Sölle (1978), pp. 74-75.

8 para hacerlo sencillo nos podemos remitir a un simple dolor de muelas y evaluar nuestra experiencia personal. 
artículo $^{9}$ en el que intentó centrar los objetivos de la medicina. El resultado fue la identificación de cuatro y entre ellos, en segundo lugar, se encontraba «el alivio del dolor y el sufrimiento causado por enfermedades»». ${ }^{10}$ Esta ' $y$ ' se enfrenta a la propuesta del profesor Stan van Hooft de la Escuela de Investigación Social de Burwood (Australia), que en 1998 publicó otro artículo contra la distinción dualista entre dolor y sufrimiento, en aras a una visión más holista de la realidad humana, que remontó hasta Aristóteles. ${ }^{11}$ Su tesis es que dolor y sufrimiento son inseparables en la experiencia humana y que el sufrimiento es el concepto fundamental; el dolor -la enfermedad, estar enfermo- es una de varias formas posibles de sufrimiento. El sufrimiento se relacionaría con el componente vegetativo del alma humana, en su opinión, y el dolor con el apetitivo. El dolor debe considerarse como sufrimiento, dice el autor, porque se corresponde con la imposibilidad de consumar los objetivos apetitivos inherentes de la persona. Para van Hooft, de ese supuesto teórico se deriva una conclusión práctica de lo más inquietante: el alivio del sufrimiento debe ser uno de los objetivos de la medicina, pero no todas las clases de sufrimiento deben ser el objeto explícito de las intervenciones médicas. El sufrimiento, en su opinión, debe entenderse como la frustración de la tendencia hacia el cumplimiento de los aspectos aristotélicos que completan nuestro ser. Tendremos ocasión de discutir esta opinión más adelante.

Actualmente, la neurociencia considera el sufrimiento como una experiencia de las personas, no de las mentes, asunto con el que estoy de acuerdo sin acotaciones. Las personas no son mentes subjetivas o espíritus inconexos con la mera materialidad. No hay mente sin cuerpo, aunque hay cuerpos -y muy capaces-que carecen de mente..$^{12} \mathrm{El}$ dualismo mente-cuerpo ha quedado obsoleto y Antonio Damasio ha ejercido de enterrador. ${ }^{13} \mathrm{El}$ interés de separar el dolor físico del sufrimiento moral no radica en una supuesta dualidad de orígenes o una añoranza cartesiana; está bastante claro, hoy en día, que ambos procesos involucran a la unidad plena de sentido que constituye la mente humana y el cuerpo del que forma parte inseparable. Damasio lo explica de otra manera en su reciente libro sobre 'El extraño orden de las cosas' publicado en 2018:

9 Ver «The Goals of Medicine» (1996), disponible a través de Internet en ‘ bit.ly/goalsofmedicine ' (consultado el 1-10-2018).

10 'The relief of pain and suffering caused by maladies '(traducción personal).

11 Ver van Hooft (1998), p. 126. Además de su interesante artículo, van Hooft (1998) había publicado en 1995 su libro Caring, an Essay in the Philosophy of Ethicas, Colorado: University Press of Colorado, para los interesados en profundizar en esta postura.

12 todas las bacterias v. gr.

13 Ver Damasio (2008): El error de Descartes. $2^{\circ}$ ed. Barcelona: Crítica 
[...] el sistema nervioso forma parte del organismo al que sirve -más específicamente, forma parte de su cuerpo- y mantiene interacciones estrechas con dicho cuerpo; $[. .$.$] esas interacciones son de una naturaleza completamente diferente$ a la de aquellas que el sistema nervioso mantiene con el entorno que rodea el organismo; la particularidad de esta relación privilegiada tiende también a ignorarse (Damasio, p. 98)

Las relaciones entre el sistema nervioso (la élite) y el cuerpo (el vulgo) deben ser reconsideradas en su totalidad. Ambos constituyen un sistema cooperativo de enorme precisión, cuya comprensión, particularmente en el aspecto relacional, está muy lejos de ser perfecta. Esta tarea, apenas iniciada por la neurociencia, requiere un abordaje multidisciplinar y abierto, libre de prejuicios. Esta es una senda abierta para una investigación filosófica que sea capaz de subirse al tren del conocimiento que pasa por su estación, bajo la amenaza de quedarse en simple apeadero. Nuestro organismo, sumamente complejo, está «constituido por sistemas cooperativos, construidos a su vez por órganos cooperativos, que están asimismo constituidos por células cooperativas constituidas por moléculas cooperativas, que están constituidas por átomos cooperativos construidos a partir de partículas cooperativas». ${ }^{14}$ Así las cosas, parece procedente intentar una cooperación entre los humanos ávidos de conocimiento, para estar en condiciones de enfrentarse a empresa de tal envergadura.

\section{SOBRE EL DOLOR FÍSICO}

El dolor es una experiencia corporal compleja de tipo sensitivo, con un fuerte componente emocional y social. Como señala Javier Moscoso ${ }^{15}$ en su libro sobre el dolor, la IASP ha pergeñado una definición ${ }^{16}$ que lo plantea como la interacción de factores fisiológicos, psicológicos y culturales, en un intento de aproximarse a una nueva visión del fenómeno doloroso más holista e integradora. Se trata de una experiencia desagradable - el componente emocional es obligatorio-, y plenamente subjetiva - de cualidad incomparable entre personas-, que asocia daño en alguna parte del organismo. Su asociación con el daño en los tejidos corporales es precisamente uno de los puntos pendientes de aclaración. La experiencia dolorosa acompaña a la estimulación de los receptores específicos para detectarla, que son bien conocidos y están dispersos por toda la superficie corporal y visceral. Sin embargo, está palmariamente

14 Ver Damasio (2018), p. 101.

15 Ver Moscoso (2012), p. 5.

16 International Association For The Study Of Pain: el dolor es «An unpleasant sensory and emotional experience associated with actual or potential tissue damage, or described in terms of such damage» (disponible en http://bit.ly/2OrKA94 -consultado el 3 de octubre de 2018-. 
acreditada la aparición de dolor claro y perfectamente discernible en ausencia de tal daño (dolor psicógeno), o en condiciones aún por explicar (dolor crónico). Por si el problema no fuera suficientemente complejo, estas situaciones se confunden con frecuencia, en una especie de contubernio biológico que resulta en malhadada experiencia para los pacientes -los que lo padecen-y quebradero de cabeza para sus asistentes -los que lo pretenden aliviar-. Mantener esta idea de correspondencia entre dolor y daño es importante, no obstante, porque todos los estímulos capaces de generar dolor son, en último término, susceptibles de dañar los tejidos.

El hormigueo, por ejemplo, es una experiencia corporal subjetiva y está relacionada con la posibilidad presente o futura de daño tisular, pero no es desagradable, por lo que no se considera dolor. Las experiencias desagradables anormales ('disestesias' ${ }^{\text {'17 }}$ ) no son necesariamente dolorosas, porque subjetivamente no tienen las cualidades sensoriales del dolor. El dolor percibido en ausencia de daño tisular - por causas psicológicas normalmente-, en cambio, es indistinguible subjetivamente del dolor de causa física, y se acompaña sistemáticamente de una respuesta emocional de desagrado, por lo tanto, debe ser considerado dolor; así es en la práctica clínica.

En cualquier caso, como tal sensación es incuestionable, lo que no implica que sea certera. En el caso del dolor, como en otras muchas situaciones, conviene diferenciar la pura sensación percibida -más o menos cercana en cualidad e intensidad al fenómeno desencadenante-, del sentimiento que genera -absolutamente irrefutable, sea acertado o no-. Ese carácter privado de la experiencia dolorosa dificulta mucho la medición del dolor, herramienta imprescindible para la evaluación de cualquier procedimiento en el enfoque científico y clínico del dolor. ${ }^{18} \mathrm{El}$ dolor en una articulación no es transparente, como el rubor (enrojecimiento de la piel), el tumor (hinchazón, bulto, acúmulo excesivo de células en cualquier lugar del organismo, independientemente de su causa y su naturaleza) o el calor. Todos ellos son signos flogóticos que sugieren la posibilidad de un proceso inflamatorio en la parte del cuerpo involucrada, pero mientras los tres últimos pueden ser objetivados por un observador entrenado, el dolor es una filiación que sólo compete al que la padece. Nadie puede argüir que existe dolor en una articulación ajena sin la conformidad del doliente.

La presencia o ausencia de dolor es obvia en unos casos, pero difícil de discernir en otros (por contención, exageración o simulación), y ello es fuente

17 Se llama 'disestesia' (IASP) a cualquier «sensación anómala desagradable, sea esta espontanea o evocada».

18 En la página web de la 'Sociedad Española del Dolor' se puede acceder a las principales herramientas con las que se trabaja en la práctica médica para medir el dolor subjetivo (bit.ly/ herramientasSED). 
de graves problemas médicos, administrativos y sociales. La medición del dolor es muy compleja, como demuestran los múltiples intentos actualmente propuestos para tal misión. De hecho, algunos autores ponen en duda la relevancia de estos cuestionarios, porque suelen traducir originales en inglés y pueden generar confusión. En un asunto donde hay que hilar muy fino este es un problema mayor, porque las preguntas enfatizan determinados componentes del fenómeno doloroso, ${ }^{19}$ o porque limitan la enorme expresividad que subyace en el fenómeno doloroso. Sirvan de ejemplo las palabras inglesas sensible, sensitive, sensitivity y sensory. Pruebe el lector hispanohablante, con conocimientos avanzados en inglés, a intentar una definición sobre la marcha. ${ }^{20}$

El dolor siempre refiere a una angustia física con múltiples modalidades (palpitante, penetrante, ardiente, martilleante, hiriente, molesto, insoportable, lancinante, rabioso, etc.), ${ }^{21}$ mientras el sufrimiento, en cambio, sugiere un estado psicológico opresivo marcado por el miedo, el temor o la ansiedad. Es importante comprender que el dolor no se corresponde exactamente con la activación del sistema de nocicepción, no equivale a una pura activación sensorial por estímulos nocivos, porque el dolor siempre es un estado psicológico, y porque la activación de los nociceptores es con frecuencia interrumpida por el sistema de autoanalgesia con el que nacemos. La presencia de dolor físico como experiencia corporal plena requiere una estimulación inicial -sea esta sensorial o no-, una conducción nerviosa con múltiples estaciones de paso y un acceso al sistema nervioso central, que es el que nos hace percibir una determinada descarga neural como dolor.

Todos los individuos, podríamos extenderlo a todas las culturas, tienen su propio temperamento particular para el dolor, su propia idiosincrasia dolorosa. Nadie sabe cómo experimenta el dolor su compañero, por muy cercano que sea en lo personal. La razón de ello es la compleja interpretación y tratamiento al que son sometidas las señales nerviosas procedentes del sistema de nocicepción. La experiencia personal y la interacción ambiental generan aprendizajes, sobre este tema y muchos otros, que las personas acumulan a su bagaje personal. El resultado no solo consiste en una diferente sensación dolorosa, sino también en una diferente externalización de la experiencia dolorosa. Por esta razón, la expresión del dolor es otra fuente de estudio del máximo interés.

19 tienden a enfatizar los aspectos emocionales o el subtipo agudo.

20 «sensible» (perceptible, sensato o consciente según el contexto, pero no sensible), «sensitive» (sensible o susceptible, pero no sensitivo), «sensitivity» (sensibilidad, que no sensitividad) y «sensory» (habitualmente sensitivo, no sensorial).

21 Todos estos términos proceden de la traducción al español del 'cuestionario de McgillMelzack' para la descripción del dolor -el más reputado de los existentes- (Ver Serrano-Atero MS et al (2002). «Valoración del dolor». En Revista de la Sociedad Española del Dolor, vol. 9, pp. 109-121.). Se puede consultar libremente en http://revista.sedolor.es/pdf/2002_02_06.pdf 
El dolor nunca es un diagnóstico, es una experiencia sensorial de fuerte impacto emocional y repercusión social. Tampoco lo es el sufrimiento. Es relativamente frecuente encontrarse en clínica con personas que refieren dolor -incluso intenso- en ausencia de cualquier daño detectable. La hipocondría, por ejemplo, la convicción de padecer una enfermedad grave, es fuente de confusión con relativa frecuencia y estamos hablando de una época, hogaño, en la que el diagnóstico de las alteraciones físicas dispone de una enorme parafernalia tecnológica. Una persona muy cercana sufrió un cuadro completo de disfagia (dificultad para tragar) y dolor tras conocer que su hermano padecía un cáncer de esófago. Una enfermera del servicio de cirugía de un gran hospital acudió a urgencias por un cuadro de dolor en hipocondrio derecho semejante en todo a una colecistitis (inflamación de la vesícula biliar), tras el fallecimiento de su padre por un cáncer de hígado. ${ }^{22}$

También es posible, aunque es más raro, encontrar pacientes con una lesión física perfectamente objetivada que no sufren dolor en contra de lo que dicta la experiencia. Es muy conocido en los servicios de urgencia el curso anodino de las apendicitis agudas en los pacientes añosos, o la sorpresa de un infarto en el electrocardiograma de un paciente que consulta por cualquier otra razón. No me refiero a los raros casos de asimbolia del dolor ${ }^{23}$ por alteración del sistema nociceptivo en alguno de sus puntos, sino a personas en plenitud de facultades cuyo sistema nociceptivo responde de manera anómala e imprevista. Las personas que sufren lesiones en las extremidades tras largos periodos de diabetes mal tratada pierden la experiencia dolorosa en las zonas más distales de su cuerpo y sufren por ello graves lesiones y mutilaciones (indoloras). Las personas infectadas por el bacilo de Hansen (leprosos) ${ }^{24}$ sufren típicamente hipoestesia -disminución de la sensibilidad-de la planta del pie, y parálisis de la pequeña musculatura de la zona, lo que conduce a úlceras plantares crónicas ('acropatía neurógena') e irreversibles.

Tenemos experiencia de lesiones sin dolor, como acabamos de ver, pero también de dolores sin lesión -sin daño físico-, que resultan muy interesantes para una investigación multidisciplinar. Hay dolores recónditos, pero igual de

22 En la página web del Ministerio de Sanidad, Consumo y Bienestar Social de España (bit.ly/CIESANIDAD) se puede acceder a la codificación de todos los diagnósticos médicos. El lector curioso puede acceder en la aplicación al listado de 'Trastornos somatomorfos' (F45), entre los que se catalogan los 'Trastornos hipocondriacos' (F45.2) y sus exclusiones. Para los hipocondriacos acérrimos adelanto que morderse las uñas no forma parte de este problema (se incluye en 'Otros trastornos emocionales y del comportamiento especificados que habitualmente tienen su inicio en la infancia y la adolescencia', F98.8).

23 Este desastroso diagnóstico se relaciona con un daño cerebral severo que genera una desconexión entre el sistema límbico y el sistema sensorial.

24173.358 casos a finales de 2016, según la OMS (http://bit.ly/2Clb85s). 
desagradables, que se escapan al bien conocido circuito nociceptivo, e interrumpen nuestras vidas de manera desconcertante y, en ocasiones, asombrosa. Me refiero, claro está, al 'dolor mental' y al 'dolor crónico' (no nos vamos a ocupar del 'dolor fingido' y su enorme cortejo de asociados). No caeré en las hipérboles del Dr. Sarno cuando asegura que «casi todos los trastornos del dolor más comunes son psicosomáticos», ${ }^{25}$ porque no estoy en condiciones de asumir tal afirmación, pero sí tengo experiencia de que el dolor procedente de fuentes psíquicas, con o sin daño tisular conocido, es realmente frecuente en problemas digestivos, migrañas, hipertensión, reumatismos, alergias respiratorias, algunas enfermedades de la piel, algunos síntomas auditivos y contracturas musculares. El dolor crónico, por ejemplo, es una de las tres categorías de dolor establecidas por la IASP, en referencia a un dolor persistente por un mínimo de seis meses que no asocia daño tisular y resulta totalmente indistinguible del dolor agudo. Tal conceptualización ya orienta a que se trata de una pesadilla para las personas que lo sufren y un rompecabezas para los profesionales que pretenden aliviarlo. Nueva fuente de preguntas muy apropiadas para la filosofía: ¿por qué existe el dolor? o, más concretamente, sabiendo que el dolor es una realidad que excede el marco de la supervivencia (lesión - dolor - reparación - salud), que no es solamente una señal de alarma ante eventos perjudiciales para la integridad del organismo: ¿qué hay de común en los diferentes tipos de dolor que se perciben como una realidad única?, ¿en qué subyace íntimamente la necesidad del dolor físico? Idénticas cuestiones afectan al estudio del sufrimiento, pero parece claro que el contexto de estudio es completamente diferente.

El 'dolor psicogénico', que se contempla expresamente en el DSM-IV$\mathrm{TR},{ }^{26}$ se caracteriza por la presencia de un dolor que no se puede explicar por un trastorno mental y en el que los factores psicológicos desempeñan un papel importante. Típicamente asocia síntomas depresivos en todos los casos, que los pacientes no suelen reconocer como tales. Esto tiene importancia, porque sabemos que los medicamentos antidepresivos son útiles para el alivio de este tipo de dolor. ${ }^{27}$ Diferente es el 'dolor psicosomático', una peculiaridad del anterior de enorme repercusión social. Se entiende como tal la producción de algún daño físico en los tejidos u órganos, responsable en última instancia del dolor, en cuya causalidad ha intervenido decisivamente el estado psíquico del

25 Ver Sarno (2013), p. 47. Resulta recomendable, en todo caso, para las personas interesadas en este tema, la lectura del capítulo segundo de su libro, que se titula 'Una breve historia de la medicina psicosomática'.

26 'Manual Diagnóstico y Estadístico de Trastornos Mentales' de la American Psychiatric Association.

27 Ver Fishbain, DA et al (1998): Do antidepressants have an analgesic effect in psychogenic pain and somatoform pain disorder? A meta-analysis. Psychosomatic Medicine, vol. 60, n. 4 , pp. 503-9. 
paciente. La importancia de esta idea es tal que actualmente se ha modificado la idea de 'enfermedad psicosomática' como tal, y se tiende a considerar que en muchas enfermedades los aspectos emocionales o psicológicos están involucrados directamente en su génesis y su progresión.

He aquí un campo abonado para la investigación cooperativa, en el que la filosofía puede orientar propuestas, conjugar hipótesis y conjurar excesos. Ello solo será posible si la investigación filosófica centra sus esfuerzos e identifica certeramente los problemas que merecen ser estudiados en función de las inquietudes de la sociedad a la que debe servir, según mi supuesto.

\section{SOBRE LA NECESIDAD DE DIFERENCIAR DOLOR FíSICO Y SUFRIMIENTO MORAL}

La palabra dolor es polisémica en español, y refiere tanto a 'sensación molesta que se siente en una parte del cuerpo' (dolor físico) como a 'sentimiento grande de pena, de tristeza o de pesar' (dolor moral). No hay objeción ninguna al uso de la palabra en los dos sentidos, porque es perfectamente lícito. La objeción se plantea a la hora de afrontar el dolor como objeto de investigación, porque el acceso al problema, la evaluación de la situación, la consideración de las circunstancias, la vivencia percibida por el organismo y las medidas que podemos emplear para vencerlo pueden ser diferentes.

Entre una percepción sensorial, más o menos localizada, que sentimos en el cuerpo por estimulación de terminaciones nerviosas especializadas y un penetrante sentimiento de penalidad, no circunscrito a un componente anatómico, que experimentamos con fuerte impacto emocional, se puede presentar un mar de diferencias y una sola similitud: su carácter profundamente personal y subjetivo.

Los sentimientos son experiencias mentales conscientes, en caso contrario los desconoceríamos. Son muchas las experiencias mentales de las que son capaces los humanos, pero en el caso de los sentimientos su contenido siempre refiere al cuerpo que los alberga y tienen un inevitable componente axiológico: los interpretamos como buenos -agradables-o malos-desagradables-, porque nunca son indiferentes o neutrales («valencia» de los sentimientos). Todos los tipos de sufrimiento, físico o psíquico, tienen una valencia negativa como componente irrenunciable, en ausencia de enfermedad o fanatismo. El sentimiento es el componente mental de la unidad interactiva que establecen el cuerpo y el cerebro, no una simple percepción del estado corporal. ${ }^{28}$

No se puede dudar que ambas realidades, bien conocidas por todos los humanos, pueden compartir espacio en nuestra mente, pero la correlación está muy lejos de ser perfecta. Todos conocemos dolores, incluso intensos, que siendo desagradables no resultan angustiosos (me acabo de pillar el dedo con

28 Ver Damasio (2018), p. 179. 
la puerta, me han pegado una patada jugando al fútbol o me he seccionado la yema del pulgar cortando una cebolla) y sufrimientos dañinos para el ánimo que cursan sin dolor físico (me han despedido del trabajo, estoy perdido en mitad de la selva o sufro cuando pienso en lo que pensarán mis padres cuando se enteren que soy un adicto a la cocaína). Soporto desde hace muchos años en silencio mi verdadera identidad transexual y tengo un espantoso dolor de cabeza por un tumor craneal son realidades que deben ser diferenciadas, por mucho que ambas generen intenso sufrimiento personal y social.

Las ampollas que afectan a los dedos de mis pies me producen un fuerte dolor físico y dificultan mi caminar, por lo que mi proyecto de completar, por fin, el camino de Santiago, tantas veces postergado, se ha derrumbado iy llevaba un año preparándolo con mis amigos! Esta situación genera sufrimiento personal, porque se apoya en una pena muy grande que me inunda, una tristeza que me invade y un pesar que me asalta, pero no porque me duelan los pies -en este caso un incidente menor-, sino porque se ha abortado mi voluntad y se ha derrumbado mi ilusión.

Tengo la intuición de que diferenciar ambos campos semánticos con claridad y abordar cada uno de los problemas en sus justos términos puede ser muy provechoso para que podamos progresar, con prudencia y cordura, en las estrategias de afrontamiento más eficaces en cada caso. El sueño puede calmar momentáneamente una emoción de pesadumbre tras la muerte de mi madre - un hipnótico o una buena técnica de meditación o un planteamiento psicoterápico adecuado pueden alterar la dinámica del proceso-, pero puede ser inútil para enfrentarse al dolor de una perforación de estómago en cuyo caso solamente el empleo de narcóticos mientras llega la reparación quirúrgica me aportará alguna ventaja. En ambos casos se sufre ciertamente, pero podemos afinar mucho más. Mezclar conceptos primarios genera alboroto, disipa nuestras potencias y confunde nuestros esfuerzos.

La palabra dolor, como hemos visto, es polisémica en dos sentidos al menos, pero esos sentidos no son sinónimos sino precisamente diferenciales. La polisemia implica diferencia de significados para una misma palabra y la sinonimia igualdad entre el significado de dos o más palabras o enunciados. Podemos tratar de la misma manera los problemas de un esposo o un marido, o hablar indistintamente de asno y borrico cuando estamos interesados en los problemas vitales de un «animal solipedo, como de metro y medio de altura, de color, por lo común, ceniciento, con las orejas largas y la extremidad de la cola poblada de cerdas», pero a nadie se le ocurriría estudiar la «agitación» social con una coctelera, emplear para la menestra cualquier «clavo» que tengamos a mano o disfrutar del encanto que aporta a la escarola una «granada» que nos ha regalado nuestro primo teniente de artillería. Para estos casos, la lingüística ha inventado el término «acepción», cosa que resulta muy útil para 
evitar confusiones. 'Sufrimiento moral' y 'daño físico' son dos acepciones de la misma palabra: dolor y, como tales, implican una diferenciación ontológica.

Cuando se ignoran las diferencias y se abordan filosóficamente el dolor y el sufrimiento social como sinónimos se pueden cometer imprudencias evaluativas como la que se aprecia en el artículo de Neftalí Suarez Rivero para una monografía sobre 'Filosofía y dolor' que se publicó en 2014: ${ }^{29}$

...las experiencias del dolor, sea la elemental manifestación de una dolencia determinada que un paciente comunica a su médico, o la de una persona que en términos vagos manifiesta que sufre una radical desesperación en su vida, o la de una comunidad a la que la violencia ha despojado de lo más querido, todas ellas, comparten un rasgo mínimo y común que cabe reducir a una expresión: pérdida del mundo, desvanecimiento de su sentido.

En esa misma publicación académica se pueden leer, también bajo el general título 'Filosofía y dolor', artículos sobre 'El sufrimiento, un verdadero maestro' de (pp. 141-158), 'Religión y violencia. La experiencia del sufrimiento en el origen de la religión' de Remedios Ávila Crespo (pp. 277-304), 'Sufrimiento, muerte y esperanza. Donde crece el peligro el hombre necesita salvación' de Dennys María Castro (pp. 391-418) o 'El dolor visto en perspectiva de la odontología estética' de María Clara Saavedra (pp. 577-595). Nada hay que objetar al respecto, pero adivino que la conclusión que pueda extraer de la lectura del libro un lector confiado que esté preocupado por la relación entre filosofía y dolor, puede ser algo imprecisa. Centremos los problemas si queremos avanzar en su resolución. Enfrentémonos a lo que nos preocupa, pero de frente, sin recovecos o adoctrinamientos.

Veamos algunos ejemplos de posible colaboración entre filosofía y ciencia, si nos atenemos al significado de la palabra dolor entendida en su acepción físico-corporal. La IASP es un grupo multidisciplinar de científicos, médicos clínicos, psicólogos, farmacéuticos proveedores de servicios sanitarios y gestores que tiene como misión, declarada en sus acuerdos estatutarios, investigar el dolor como sujeto de estudio y, sobre todo, transferir el conocimiento generado a la práctica sanitaria. La IASP es la referencia para temas relacionados con el dolor de la Organización Mundial de la Salud. No es la única organización de profesionales que se dedica en exclusiva al tema que nos ocupa, pero si es la más importante. ${ }^{30}$

29 Ver Suárez Rivero, Neftalí David (2014): «Dolor y sufrimiento social: una exploración a partir del lenguaje», pp. 159-213. En Cardona Suárez, Luis Fernando: Filosofía y dolor. Bogotá: Pontificia Universidad Javeriana.

30 Otras organizaciones son: la 'International Association for the study of Pain' (IASP) http://www.iasp-pain.org; la 'European Federation of IASP Chapters' (EFIC); http://www.efic. 
$\mathrm{Su}$ orientación es fundamentalmente práctica. Este primer punto es crucial, porque abre el camino a establecer una colaboración en este difícil e interesante itinerario con la filosofía. La filosofía se caracteriza por su enorme capacidad para generar visiones holistas y componer estructuralmente sistemas de pensamiento a partir de conceptos aislados. Mediante la reflexión filosófica se pueden atisbar construcciones mentales creativas e integradoras que ayuden a centrar los esfuerzos en orden a una meta de interés general. Una voluntad de beneficiar a la sociedad en su conjunto es, a mi juicio, necesaria para una rama del conocimiento que pretenda subsistir con apoyo social. Los desarrollos solipsistas orientados a satisfacer egos de gran tonelaje o requisitos académicos pueden generar satisfacción personal, pero suelen ser poco valorados por la voluntad general.

La filosofía, tal como yo la entiendo, debe librarse del abigarrado engranaje teológico-místico que la acoraza, descender al albero de la vida y orientarse al servicio de la sociedad de la que depende y a la que sirve. A través de la filosofía conectamos directamente con un pensamiento crítico -reflexivo, distanciado, englobador-, orientado a explicar racionalmente la realidad en base a pruebas y argumentos. A través del esfuerzo de los filósofos llegamos a concepciones universales de lo que son casos particulares, nos acercamos a lo compartido y entroncamos con lo dinámico desde puntos de vista abstractos (mentales, construidos). La filosofía ayuda a analizar la realidad, a comprenderla y ordenarla, a centrar lo cambiante y plural y a aprehender lo que se resiste.

El filósofo venezolano Carlos Ulises Moulines explica con gran fortuna, a mi entender, la idea de que la filosofía puede ser un modo de reflexión muy adecuado para el estudio del componente subjetivo del dolor, debido a su carácter general, abstracto y reflexivo, en una entrevista que concedió en 1991:31

[...] creo que cualquier persona que logre un mínimo de distancia respecto a su propia vida, a su propio lugar en el mundo, a las propias herramientas de trabajo que utiliza en su quehacer cotidiano,[...] se dará cuenta de que más allá de los resultados inmediatos que se pueden obtener con una eficiencia técnica, está el deseo de aclarar los conceptos con los que nos enfrentamos al mundo y aclararlos de una manera sistemática, crítica, en el sentido que yo la entiendo, que nos ayude a ubicarnos a nosotros mismos en el mundo, en la sociedad en la que estamos y también en la historia de la que procedemos (Ibarra, 1992).

org; la 'Federación Latinoamericana de Asociaciones pare el Estudio del Dolor' (FEDELAT) http://www.galenored.com/; o la 'Sociedad Española del Dolor'; http://www.sedolor.es.

31 Ver Ibarra A. (1992): 'Carácter y función de la filosofía'. En THEORIA, segunda época, vol. VII, n. 16-17-18, tomo A, pp. 25-40. 
La filosofía, tal como la concibe el Profesor Moulines, es una reflexión recursiva, que en el caso del dolor se puede aplicar a la investigación científica que sobre el mismo tema ha incrementado notablemente nuestros conocimientos sobre este tema (conocimientos que en ningún caso procede obviar). ${ }^{32} \mathrm{El}$ filósofo analiza teorías, métodos y conceptos en base a una metodología propia que complementa y eleva el saber científico. Más importante aún, la ciencia genera un mar de conocimientos puntuales que es necesario organizar para que el resultado final sea verdaderamente útil a las personas que se enfrentan con los problemas reales. La ciencia se equivoca en muchas ocasiones, genera desconciertos, sufre lagunas y propone incoherencias, que el filósofo adecuadamente encaminado puede ayudar a reorientar. Pero para que esto suceda, el primer paso debe ser compartir objetivos, plantear adecuadamente los problemas y centrar la reflexión sobre problemas claramente definidos y comprendidos.

En las facultades de medicina, hasta donde yo conozco, se afronta muy escasamente el problema del sufrimiento y, sin embargo, se estudia el tema de la anatomía, fisiología, fisiopatología y terapéutica del dolor. El problema del sufrimiento no se trata directamente en la educación médica. Es más, la cuestión del sufrimiento y su relación con la enfermedad orgánica rara vez se ha abordado en la literatura médica. ${ }^{33}$ En un interesante artículo publicado en 1982, Eric Cassel ${ }^{34}$ estudia la naturaleza y las causas del sufrimiento en pacientes sometidos a tratamiento médico y distingue con precisión el sufrimiento físico del sufrimiento en general (pain and suffering). El sufrimiento es experimentado por personas, no meramente por cuerpos, amenaza seriamente la integridad de las personas y puede incluir dolor físico, aunque no está limitado a él. En medicina, de hecho, ser incapaz de diferenciar una fuente de sufrimiento física de una psíquica puede ser causa de una mala atención y un tratamiento inadecuado. No todos los enfermos -personas con una alteración de su salud a cualquier nivel y de cualquier intensidad- sufren, como el paciente afectado por un quiste pilonidal que desea solucionarlo antes de su boda o el que necesita que le extirpen un lipoma para poder ingresar en el servicio militar. Sufrimiento siempre es padecimiento, pero puede ser pena, puede ser dolor, puede ser las dos cosas a la vez o ninguna. El sufrimiento se puede asociar con alteraciones de la salud ajenas al dolor, lo cual es muy frecuente, como la disnea (falta de aliento), la anorexia (falta de apetito), la disfunción eréctil (falta de erección) o la constipación (falta de evacuación intestinal).

32 Ver Ibarra, p. 34.

33 Ver Cassel (1982), p. 639

34 Eric J Cassel es profesor emérito de Salud Pública en la Universidad de Cornell y profesor adjunto en la Facultad de Medicina de la McGill University. Además del artículo ya reseñado, publicó en 1991 un libro desarrollando su postura: The Nature of Suffering, Oxford: Oxford University Press. 
El doctor Eric Cassel propone una «visión subjetiva» del dolor, que le aboca a una visión desesperanzada de la utilidad de la medicina cuando se enfrenta al problema. Al tratarse de un concepto puramente subjetivo, plenamente fenomenológico, las posibilidades de enfrentarse con él, en toda su complejidad, se escapan de las capacidades de la ciencia, que no puede ir más allá de extirpar una sensación que no comprende. Ello conduce a grandes retos y penosos contrasentidos, como la provocación indeseada, pero inevitable, de dolor a través de efectos secundarios, o los resultados de tratamientos agresivos o mutiladores. Interesante planteamiento sobre el dolor como campo abonado a la investigación filosófica.

Como contrapartida a la propuesta de Cassel, el filósofo australiano Stan van Hooft presenta una visión objetiva de la experiencia del sufrimiento de la que se pueden extraer importantes reflexiones. En su artículo de 1998 defiende que el sufrimiento (fenómeno que engloba todo tipo de dolor, según afirma) se debe considerar como la frustración de la consecución de algunos de los grandes retos aristotélicos que constituyen la experiencia vital de las personas: biológico, apetitivo, deliberativo y contemplativo. El fracaso en la consecución de alguna de estas plenitudes genera indefectiblemente sufrimiento porque impide el pleno desarrollo del ser. Sin entrar en un análisis profundo de este interesante artículo salta a la vista una conclusión que me resulta imposible aceptar. Si el sufrimiento es objetivable en su totalidad, puede ser identificado por una tercera persona, las decisiones sobre el sufrimiento ajeno pueden ser legítimamente asumidas por observadores externos. Enjuiciar la experiencia dolorosa -el sufrimiento en general- desde perspectivas ajenas al doliente no me parece una conclusión aceptable.

El dolor y el sufrimiento comparten un cierto aire de familia, family resemblance, como creía Wittgenstein; pero los progenitores no son los mismos. Todos los sufrimientos y todos los dolores comparten el comedor, pero cada uno tiene su propia habitación. Se juntan frecuentemente en los pasillos, pero habitan diferentes campos de la realidad -que no siempre son congruentes-, como dos hermanos que salen juntos a pasear pero luego se retiran a su habitáculo personal. La frontera de clase entre ambos conceptos es indefinida, pero es real; hay indudablemente rasgos comunes, pero no comparten una esencia ideal.

Una tercera perspectiva interesante sobre el concepto de sufrimiento -a la que su proponente llama 'intuitiva'- consiste en acercarse a la experiencia dolorosa considerando los usos que el término tiene en un juego del lenguaje (el del lenguaje ordinario, en este caso). El significado de dolor y sufrimiento, o cualquier otra palabra, está determinado por el modo en que se usa. Steven Edwards, desde la Escuela de Ciencias de la Salud de Gales-Swansea, se basa en el giro pragmático de Wittgenstein para aportar su opinión de que el sufrimiento tiene un fuerte componente fenomenológico - conlleve o no dolor-, y el 
dolor no es condición necesaria ni suficiente para el sufrimiento. El sufrimiento, por ejemplo, refiere a dos características, consagradas por el uso habitual del término, que son ajenas a la idea general de dolor: siempre es de una mayor duración y necesariamente ocupa todo el espectro de la mente. ${ }^{35}$

Estas discrepancias constituyen excelentes razones, tal como yo lo veo, para profundizar en la experiencia propiamente dolorosa con armas ajenas al diagnóstico clínico, la farmacopea química o la disección quirúrgica. Urge, a mi modo de ver, una aproximación multidisciplinar a la experiencia dolorosa -a la experiencia del dolor físico-, que sume por fin la reflexión filosófica a esta complicada batalla. En el caso de que la capacidad pensante y argumentativa de los filósofos decida apoyar los esfuerzos por acabar con la plaga del sufrimiento físico humano los partidarios del mismo deberán abstenerse.

\section{Conclusiones}

Mi alma es como una orquesta oculta; no sé qué instrumentos rechinan y tocan en mi interior, cuerdas y arpas, timbales y tambores. Solo me reconozco como sinfonía.

(Fernando Pessoa) $^{36}$

No parece razonable dudar de la influencia de las creencias en la experiencia personal del dolor, opinión que comparten la Asociación Internacional Para El Estudio Del Dolor y otros investigadores especializados en esta cuestión, tal como he mencionado en el texto. Sin embargo, la vivencia personal de una experiencia subjetiva no debe confundirse con la realidad de la misma; y no se puede exigir a la persona que se haga cargo de un sufrimiento que no es parte necesaria de la experiencia vital en la que se desarrolla.

El dolor y el sufrimiento son nuestros infatigables y desagradables compañeros de existencia, aunque no son los únicos. Parece humano combatirlos y buscar una trayectoria vital más acorde con nuestra inclinación biológica al bienestar, a la ausencia de dolor, a la huida del sufrimiento. No es esta una opción unánime, ciertamente, y poderosas influencias culturales, particularmente el cristianismo, se empeñan en encontrar favorecedor lo que a algunos nos resulta aberrante:

Señor, vemos en los castigos que han venido sobre nosotros que tu estás enojado con toda razón contra nosotros. Ya que tu eres justo no atormentas a los tuyos sin razón. [...] Pues bien, aunque nos castigaras todavía más severamente de lo

35 Ver Edwards (2003), pp. 64-66

36 Pessoa, Fernando (1999): Libro del desasosiego. Barcelona: Planeta. 
que hasta ahora has hecho...confesamos, a pesar de todo, que sucede esto con toda justicia y no negamos que nos lo hemos merecido. ${ }^{37}$

No objeto la libertad de cada uno para vivir la vida según sus creencias, pero sugiero que, para intentar comprender mejor los asuntos que nos afligen, resulta conveniente discernir entre realidades que se diferencian en muchos aspectos, pero sobre todo que requieren diferentes estrategias de afrontamiento. Si el dolor, el sufrimiento o ambos son deseables para la evolución de las personas es una decisión personal, pero si pretendemos avanzar en el conocimiento de nuestras miserias conviene ser más selectivo a la hora de investigarlas. Es necesario, en mi opinión, ser consciente de estas dos dimensiones que nos plantea el dolor, para poder afrontar los retos que conlleva cada una de ellas de manera más efectiva. Diferenciar dolor y sufrimiento y abordar cada uno de los problemas de manera diferenciada puede ser provechoso a la hora de enfocar el problema de su afrontamiento.

He intentado, a lo largo del artículo, sugerir preguntas que juzgo idóneas para una investigación multidisciplinar relacionada con la experiencia del dolor físico: ¿cómo es posible que, bajo determinadas circunstancias, el dolor pueda ser gratificante?;cuál es la raíz ontológica de la cooperación entre mente y cuerpo, a la luz de los recientes descubrimientos de la neurociencia?¿qué hay de común en los diferentes tipos de dolor que se perciben como una realidad única?¿por qué existe el dolor?¿es el dolor una estrategia de supervivencia, o hay algo más?; o, mejor aún, ¿en qué subyace íntimamente la necesidad del dolor físico? Para aproximarse con alguna posibilidad de éxito a un problema es necesario comenzar por enfocar la cuestión de la manera más estricta que sea posible. Formular correctamente el problema de investigación en forma de pregunta concreta, bien planteada y verosímilmente fecunda es una buena estrategia de trabajo; pero, para ello, centrar la inquisición en un campo cuidadosamente perfilado es una obligación.

\section{BIBLIOGRAFÍA}

CALLAHAN, DANIEL (1996): «The Goals of Medicine: Setting New Priorities». En The Hastings Center Report, vol. 26, n. 6, pp. S9-S13

CARDONA SUÁREZ, LUIS FERNANDO (2014) -editor académico-: Filosofía y dolor. Bogotá: Pontificia Universidad Javeriana.

CASSEL, ERIC J (1982): «The nature of suffering and the goals of medicine». En The New England Journal of Medicine, vol. 306, n. 11, pp. 639-45.

CERVERO, FERNANDO (2012): Understanding pain. Cambridge: MIT Press.

37 Oración de Calvino recogida por Dorothee Sölle en su libro 'Sufrimiento'. Ver Sölle (1978), p. 16. 
DAMASIO, ANTONIO (2018): El extraño orden de las cosas. La vida, los sentimientos y la creación de las culturas. Barcelona: Planeta.

DÍAZ ROMERO, PAULA (2015): «Consideraciones sobre el dolor desde una perspectiva fenomenológica». Co-herencia, v. 12, n. 23, pp. 89-106.

DOMÍNGUEZ, VICENTE (2006) -editor-: El dolor. Los nervios culturales del sufrimiento. Oviedo: EdiUno (ediciones de la Universidad de Oviedo).

EDWARDS, STEVEN D. (2003): «Three concepts of suffering». En Medicine, Health Care and Philosophy vol. 6, pp. 59-66.

GONZÁLEZ, MOISÉS (2006) - editor-: Filosofía y dolor. Madrid: Tecnos.

IASP Task Force on Taxonomy (1994): «Part III: Pain Terms, A Current List with Definitions and Notes on Usage». En Classification of Chronic Pain, Second Edition, IASP Press, Seattle, pp. 209-214.

IBARRA, ANDONI (1992): «Carácter y función de la filosofía (entrevista a C. U. Moulines)». En THEORIA, vol. VII, n. 16-17-18, tomo A, pp. 25-40.

MOSCOSO, JAVIER (2012): Pain. A cultural history. Hampshire: Palgrave MacMillan.

PARÍS, CARLOS (1992): «Mi visión del filosofar». En THEORIA, vol. VII, n. 16-1718, tomo A, pp. 12-24.

SARNO, JOHN E (2013): La mente dividida. Málaga: Sirio.

SÖLLE, DOROTHEE (1978): Sufrimiento. Salamanca: Sígueme.

VAN HOOFT, STAN (1998): «Suffering and the goals of medicine». En Medicine, Health Care and Philosophy vol. 1, pp. 125-131.

Francisco Javier Suso Alea es licenciado en Medicina por la Universidad de Valladolid, Doctor en Medicina por la Universidad de Salamanca y facultativo especialista del Área de Cirugía General del Complejo Hospitalario de Vigo del Servicio Gallego de Salud. Experto Europeo en Gestión de la Calidad y Profesor de la Escuela de Enfermería del Sergas en la Universidad de Vigo entre 1991 y 1998, actualmente se encuentra cursando el Grado de Filosofía en la Universidad de Salamanca. Su interés investigador se centra en las aportaciones que puede ofrecer la Filosofía al afrontamiento del dolor en los seres humanos.

Líneas de investigación:

Filosofía del dolor, Bioética: Ética de la investigación clínica

Email:

susoalea@usal.es 
